\title{
Influence of glass beads filler and orientation process on piezoelectric properties of polyethylene composites
}

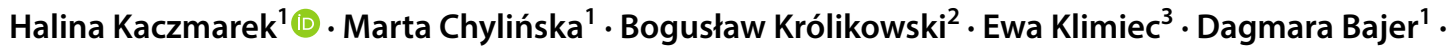 \\ Jolanta Kowalonek ${ }^{1}$
}

Received: 9 August 2019 / Accepted: 29 October 2019 / Published online: 15 November 2019

(c) The Author(s) 2019

\begin{abstract}
The effect of silica filler (in the form of glass beads) on polyethylene composite properties has been studied. Conditions for obtaining polyethylene-based composites in the extrusion process were developed. Two types of such composites were prepared: non-oriented and oriented in the uniaxial stretching process in a ratio of 3:1. The morphology, microstructure (including crystallinity degree), mechanical resistance, and thermal stability of the obtained composites containing 2.5-10\% of the filler were analyzed by the scanning electron microscopy connected with energy dispersive X-ray analysis, X-ray diffraction, differential scanning calorimetry, thermogravimetry methods, and tensile tests. In order to induce piezoelectric effect, the samples were charged with a direct current of $100 \mathrm{~V} / \mu \mathrm{m}$ at $85^{\circ} \mathrm{C}$. The piezoelectric properties of the polyethylene composites were determined by the measurement of charge and voltage of current generated during action of stress up to $120 \mathrm{kPa}$. Piezoelectric coefficients, $\mathrm{d}_{33}$ and $\mathrm{g}_{33}$, versus applied stress were determined and the stability of electrets stored during 2-5 months was tested too. The best piezoelectric properties were found for medium-density polyethylene composite containing $5 \%$ of glass beads.
\end{abstract}

\section{Introduction}

The innovative materials with the designed tailored utility properties determine the development of modern technologies, for instance, piezopolymers, can find many practical applications such as sensors, actuators, or transducers, in medicine, electronics, forensic, military, and space industries [1-3]. The piezomaterials, named also piezo-electrets, are characterized by the specific internal structure allowing for polarization and accumulation of electric charges, which can be transformed into mechanical forces and vice versa.

Nowadays, they can be used for the production of microelectronic wireless equipment with very low power consumption or even as current generating devices owing to

Halina Kaczmarek

halina@umk.pl

1 Faculty of Chemistry, Nicolaus Copernicus University in Toruń, ul. Gagarina 7, 87-100 Toruń, Poland

2 Łukasiewicz Research Network - Institute for Engineering of Polymer Materials and Dyes - Toruń Division, ul. M. Skłodowskiej-Curie 55, 87-100 Toruń, Poland

3 Institute of Electron Technology - Kraków Division, ul. Zabłocie 39, 30-701 Kraków, Poland the piezoelectric effect resulting from the reversible conversion of mechanical vibrations into electrical impulses. The future functions of the piezoelectric polymers, such as energy harvesting and storage or energy-efficient solid-state electronic refrigeration, should be mentioned [4-6] because it is related to the search for alternative, ecological energy sources, which is one of the main word problems.

Moreover, the piezoelectric effect can be used in the systems that are able to restore the energy dissipated during the car traffic, which may be important due to the rapid development of motorization. Appropriate technological solutions in this field have led to the construction of energy-generating roadways [7-9]. The possibility of transforming wind energy or falling raindrops is a great challenge as well [10].

Piezoelectric materials have applications in biotechnology and medicine. As it was found over 50 years ago, human tissues (bones, muscles, ligaments, tendons, and cartilages) exhibit piezoelectric properties; therefore, the design of synthetic materials with analogous properties is of great significance in regenerative medicine or robotic system construction [11-13].

In addition to ionic and polar substances, there are also non-polar compounds, e.g., polymers including polyolefin, that exhibit the piezoelectric effect [14-16]. Polymers, 
which are mostly dielectrics, have many valuable advantages such as flexibility, low density, good mechanical properties, the ability to form different shapes, and chemical resistance.

The properties of the polyolefin result from the chemical structure (e.g., the type of branching influencing also the crystallinity) as well as from the presence of modifying additives and processing aids. The crystallinity of polymers depends on the molecular weight, dispersity, and the thermal history of the sample. Generally, the high molecular ordering leads to higher tensile strength, stiffness, and hardness but it simultaneously causes the decrease in the polymer elasticity. At the same time, the presence strength of crystalline phase greatly affects other properties such as brittleness, thermoplasticity (and therefore also processability), thermal and photochemical stability, and optical properties. Introduction of higher olefins (containing 4-10 carbon atoms), as co-monomers in copolymerization with ethylene, leads to the controlled branching of the polyethylene (PE) chains, causing the reduction of macromolecular ordering, and consequently a decrease in brittleness and an increase in the film transparency.

As the research demonstrated, the piezoelectric effect often resulted from the cellular structure of the polymeric film. The voids created inside the polymer were responsible for the formation of stable dipoles. Such voided morphology contributing to the creation of electrets in the polymers has been also described by other authors [17-22]. To ensure suitable functional features of products, including piezoelectric properties, appropriate amount of amorphous phase should occur in the polymer structure because this phase is responsible for adequate flexibility of the system. Small variations in the composite structure (e.g., structural defects and imperfections), depending on manufacturing conditions, influence the designed properties of the product; therefore, it is vital to determine exactly how to manufacture them.

The purpose of this research was to obtain and characterize the properties of piezoelectric composites made by extrusion of two types of polyethylene, PE (high and medium density-HDPE, MDPE) filled with glass beads. PE was chosen due to its wide availability, well-known processing and low price, which should guarantee the obtaining cheap piezoelectric materials. Moreover, the extruded films were uniaxially oriented in order to increase the crystallinity. The main purpose of the glass beads application as a filler was to obtain the piezoelectric PE-based composites; however, this filler had an advantageous effect on other material properties and processing too. It is known that, the polymer with GB displays the improved strength and stiffness, diminished shrinkage, and enhanced flame retardancy as well as easier processing [23-26]. Its action strongly depends on the particles size and shape, distribution in a polymer matrix, and interactions with the macromolecules.

\section{Experimental part}

\subsection{Materials}

High-density polyethylene (HDPE) Tipelin FS 471-02 (density $d=946 \mathrm{~kg} / \mathrm{m}^{3}$ ) and medium-density polyethylene (MDPE) Tipelin FS $383-03\left(d=938 \mathrm{~kg} / \mathrm{m}^{3}\right)$, produced by MOL Petrochemicals Co. Ltd., Hungary, have been used as a matrix. According to the information, provided by the manufacturer, both materials were copolymers with hexene- 1 and contained antioxidant and acid scavenger [27, 28].

Silica filler in the form of glass beads MinTron 7 (RockTron, United Kingdom, $\mathrm{D}_{90 \%}<20-30 \mu \mathrm{m}$, abbreviation GB) [29] was added to the polymer in amount of $2.5 \%, 5 \%$, or $10 \%$ by weight.

\subsection{Preparation of polyethylene composites}

The polymer and the filler have been mixed to form composites and then the obtained composites have been pelletized in co-rotating twin-screw extruder of the type Bühler BTSK $20 / 40 \mathrm{D}$ at $190-195^{\circ} \mathrm{C}$. These pellets were taken to extrude a cast film using a single-screw extruder-Plastis Corder PLV 151 Brabender.

The part of the samples were uniaxially oriented in a ratio of 3:1 at room temperature with the usage of the device produced by Institute for Engineering of Polymer Materials and Dyes-Toruń, Poland.

\subsection{Characterization of polyethylene composites}

The sample structure was examined by scanning electron microscopy (SEM) Jeol $5500 \mathrm{~L}$ operating in high vacuum and with accelerating voltage of $30 \mathrm{kV}$. The ETD high pressure detector with the secondary electrons (SE) detection was used. SEM photos of representative areas were taken. Energy dispersive X-ray (EDX) analysis has been simultaneously performed to observe the elemental composition of the specimen surface.

The composite interior was imaged after brittle fracture of the samples in liquid nitrogen. The tested sample surfaces were sputtered with gold.

X-ray diffraction (XRD) patterns were obtained by X'PERT Pro Philips diffractometer (with $\mathrm{Ni}$-filtered $\mathrm{Cu}$ $K_{\alpha 1}$ radiation; wavelength $1.54056 \AA$ ) in the range of $2 \theta=10^{\circ}-60^{\circ}$ by the step of $0.02^{\circ}$.

The recorded XRD profiles have been used for determination of the degree of crystallinity $\left(\mathrm{X}_{\mathrm{XRD}}, \%\right)$ of $\mathrm{PE}$ expressed as the ratio of the peak area of the crystalline phase to total surface area under the curve (which is a sum of crystalline peaks areas and amorphous halo). The 
calculations were made for the range of $2 \theta=10^{\circ}-30^{\circ}$ after mathematical analysis of the curve for the component peaks. Curve fitting has been done using Voigt function.

The PE crystallites size, using the main signal (110), has been calculated from Sherrer equation [30]:

$\mathrm{L}_{\mathrm{hkl}}=\frac{0.9 \lambda}{\cos \theta}$

where $\mathrm{L}_{\mathrm{hkl}}$ is the crystallites size, $\lambda$ is the wavelength of $\mathrm{X}$-ray, $\beta$ is the full width at half maximum (FWHM), $\theta$ is the Bragg angle.

Differential scanning calorimetry (DSC) has been done using Mettler Toledo, DSC1 Star System. The samples were tested in 3 runs: 1 -heating, 2 - cooling, and 3 reheating in the temperature range of $0-300{ }^{\circ} \mathrm{C}$. After completion of the first heating and cooling cycle, the sample was held at a constant temperature for $3 \mathrm{~min}$. The heating and cooling rate was $10 \% \mathrm{~min}$. The nitrogen flow rate was $60 \mathrm{ml} / \mathrm{s}$.

The crystallinity degree $\left(\mathrm{X}_{\mathrm{DSC}}, \%\right)$ has been calculated based on the determined heat of fusion $(\Delta \mathrm{H})$. The value of $\mathrm{PE}$ heat of fusion per unit volume $\left(\Delta \mathrm{H}_{100 \%}\right)$ taken from the literature was $293 \mathrm{~J} / \mathrm{g}$ [31].

Mechanical strength was tested using TIRAtest 27025 tensile apparatus according to the standard PN-EN ISO 5271:2012. In the initial stage, i.e., in the $0-2 \%$ of elongation, corresponding to the linear region in which Hooke's law is applicable, the feed speed of crosshead was $1.0 \mathrm{~mm} / \mathrm{min}$ to determine the exact modulus of elasticity $\left(E_{t}, M P a\right)$. Then, the speed increased to $100.0 \mathrm{~mm} / \mathrm{min}$ and was held until the sample was broken. The length of the measuring section was $50 \mathrm{~mm}$, the head load was $3 \mathrm{kN}$. In addition to $\mathrm{E}_{\mathrm{t}}$, the maximum stress $\left(\sigma_{\mathrm{M}}, \mathrm{MPa}\right)$, stress at break—ultimate strength $\left(\sigma_{\mathrm{B}}, \mathrm{MPa}\right)$, maximum elongations $\left(\varepsilon_{\mathrm{M}}, \%\right)$, and elongation at break (ultimate elongation $\varepsilon_{\mathrm{b}}$, \%) have been determined. The obtained results are an average of 6-10 measurements.

Thermal stability was studied in nitrogen atmosphere using SDT 2960 Simultaneous TGA-DTA Thermal Analyser (TA Instruments, USA). The heating rate was $10 \%$ min and the temperature range was up to $700{ }^{\circ} \mathrm{C}$. The temperature of the degradation onset $\left(\mathrm{T}_{\mathrm{o}}\right)$ was determined from the intersection of tangents to the TG curve, while the maximal rate of thermal degradation $\left(\mathrm{V}_{\max }, \% / \mathrm{min}\right)$ and the corresponding temperature $\left(\mathrm{T}_{\max }\right)$ was read from DTG. The nature of the transformation (exo- or endo-) as well as the melting temperature was obtained from the DTA curves registered simultaneously with TG.

FTIR spectra have been recorded using Vertex 70v with RT-DLaTGS Wide Range detector and ATR device, Bruker Optik, with diamond crystal. The mathematical distribution of the complex spectrum into components has been done using Voigt function to get the best fit to the recorded spectrum shape.
To generate the piezoelectric properties, the samples were placed between two contact electrodes with an area of $10 \mathrm{~cm}^{2}$ and then they were polarized in a fixed electric field of $100 \mathrm{~V} / \mu \mathrm{m}$ at $85{ }^{\circ} \mathrm{C}$. The thickness of the films was $\sim 130 \mu \mathrm{m}$ for the non-oriented samples and $\sim 80 \mu \mathrm{m}$ for the oriented ones. The piezoelectric charge (q, pC) and voltage $(\mathrm{U}, \mathrm{V})$ were measured using a stress increasing up to $120 \mathrm{kPa}$. The device was consisted of an electromagnetic actuator, Tektonikx AWG 420 generator (Arbitrary Waveform Generator), Mera Tronik P334 power amplifier, XFL212R force sensor, ADR 154 amplifier, Keithley 6517A electrometer, and LeCroy LT-341 oscilloscope. The force acted in the direction perpendicular to the sample surface was consistent with the direction of the electric field. From the above measurements, two piezoelectric coefficients were calculated: charge coefficient $-\mathrm{d}_{33}=\mathrm{q} / \mathrm{P}(\mathrm{pC} / \mathrm{N})$ and piezoelectric voltage coefficient $-\mathrm{g}_{33}=\mathrm{q} /(\mathrm{P} \cdot \mathrm{d})[\mathrm{Vm} / \mathrm{N}]$, where $\mathrm{P}$ is stress $(\mathrm{Pa})$ and $\mathrm{d}$ is sample thickness $(\mathrm{m})$.

Stability of electrets was studied during 2-5 months, taking measurements every few days. At least five samples of the same type have been tested simultaneously to check the piezoelectric properties and the result is the averaged value from three tests.

\section{Results and discussion}

\subsection{Preparation and characterization of the polyethylene composites}

We have made many attempts to obtain the polyolefin-based composites with a mineral filler for the production of piezoelectric elements by classic processing methods. The best way was to use the pelletizing extrusion method preceded by careful mixing of the ingredients (a powdered glass bead filler with virgin PE granulate) at room temperature. The temperature and the extrusion speed were selected so as to obtain a homogeneous material without any visual defects on a macroscopic scale.

We have found that the pelletizing extrusion process was optimal with the usage of a twin-screw extruder at head temperature of $190{ }^{\circ} \mathrm{C}$ (MDPE) and $195^{\circ} \mathrm{C}$ (HDPE) and at a speed of $250 \mathrm{~s}^{-1}$. In the second processing step, a singlescrew extruder was working at the temperature range of $225-235^{\circ} \mathrm{C}$ along the extruder cylinder and a head.

The orientation of the composite films in a ratio of $3: 1$, carried out continuously at the temperature $120-80{ }^{\circ} \mathrm{C}$ (including heating and then cooling) gave the best results. It was indicated that maintaining such conditions ensured the good quality of the composites films and the repeatability of their properties. Higher speed of transport of the composite film may result in breaking the sample, which was noticed particularly at the highest filler content $(10 \%)$. 


\subsection{Morphology of the polyethylene composites studied by SEM/EDX}

Figure 1 presents surface and internal structure of the filler (glass beads), and the PE composites (non-oriented and oriented). The filler is seen in the form of regular spherical glass particles with a diameter of several micrometers (Fig. 1a). The initial PE samples (both HDPE and MDPE) have homogenous surfaces and do not show any significant morphological details, except for the corrugation of the surface in the case of the oriented films. When viewed at high magnification, a partial lamellar order in the perpendicular direction to the stretching direction is seen for these films (Fig. 1c, g).

The PE composites exhibit completely different morphology due to the introduction of the glass beads into the matrix. These particles are dispersed in the PE matrices, but as one can see, there are the empty spaces around them, which can be a result of the lack of adhesion and miscibility between the fully hydrophobic macromolecules and the silica. $\mathrm{SiO}_{2}$ has polar $\mathrm{Si}-\mathrm{O}$ bonds; however, due to the symmetry of these bonds, the dipole moments cancel out [32]. During poling process, this symmetry is disturbed, resulting in permanent dipoles formation. Therefore, the composites produced have a heterogeneous structure in which the glass particles and microvoids are dispersed in the polymer matrix. Similar porous structure was observed in the case of polypropylene composites as a result of the addition of rigid filler particles to this polymer [17, 18]. The formation of voids was described in detail in the article by Arencón and Velasco [33].

The heterogeneity of the studied composites was confirmed by the EDX combined with SEM. Most observed peaks are X-rays given off as electrons return to the $\mathrm{K}$ electron shell (K-alpha line). The images obtained by this method show how individual elements are distributed on the sample surfaces, which is seen on the example of HDPE $+2.5 \%$ GB in Fig. 2. As can be seen, the glass beads, represented by $\mathrm{Si}, \mathrm{O}, \mathrm{Al}$, and $\mathrm{Fe}$, are evenly distributed in the whole mass of the composite without creating bigger agglomerates.

Sample orientation results in a change of both the surface and the internal structure (Fig. 1c, f, i). Small folds, visible under the microscope, appear on the surface, which is related to the stretching of the chains in the amorphous phase leading to a fibrous structure, while the crystalline areas remain intact initially. When stretching is continued, also crystalline phase can experience reorganization and even some deformation like rotation or shear and intralamellar slipping [33]. Generally, the orientation process leads to the growth in ordering of both the lamellar crystalline areas and stretched chains in the amorphous phase, which is commonly manifested in the rise of the degree of crystallinity. Moreover, the increase in the speed of stretching can cause further changes which may also occur within the lamella aggregates, until the sample ruptures. In our research, optimal modification of the microstructure was obtained by stretching three times $(3: 1)$.

Orientation of polymer films at elevated temperature is an irreversible process, although some relaxation processes may occur after cooling to room temperature. Furthermore, the stretching process is also accompanied by a deformation process. Crazes and microcracks may appear in the polymer. These defects are the precursors of microporosity and they may affect the mechanical properties of the product. Such features were not observed in the SEM images of the unmodified HDPE and MDPE. However, a cellular structure was formed in the case of PE composites. The holes with micrometric sizes enlarged during the orientation taking rather ellipsoidal shapes, which was a result of partial disconnecting GB from macromolecules and a cavitation process. The nature of this process occurring in the amorphous phase of the stretched (oriented) films at the temperature above glass transition was described in details in articles by Pawlak et al. $[34,35]$. The formation of cavities is associated with an increase of the free volume of a polymer as a result of rearrangement of unordered flexible macromolecules. Similar effect of an inorganic filler on internal morphology has been observed in oriented films of isotactic polypropylene [17, $18,36]$.

\subsection{Crystallinity analysis by XRD/DSC}

The shapes of XRD patterns obtained for the HDPE composites were similar to these for the MDPE composites, which indicated that the basic structure of PE crystallites was almost the same for all samples. Some small variations concerned the peak intensities and their ratios. Figure 3 shows XRD curves of the selected HDPE composites (non-oriented and oriented) and GB.

The XRD curves of the MDPE and HDPE films exhibit two main signals at $2 \theta=21.7^{\circ}$ and $24.0^{\circ}$, corresponding to 110 and 200 spacing (Fig. 3). Moreover, in the oriented PE films and the composites, an additional minor peak at about $2 \theta=30^{\circ}$ is observed. The results indicate that both PE's have orthorhombic symmetry [37, 38].

The share of the first main signal (at $21.7^{\circ}$ ) is approx. $50 \%$, whereas the second one (at $24.1^{\circ}$ ) is only $5-7 \%$, the rest is a fraction of amorphous halo (43-45\%). The recorded experimental XRD patterns are typical of PE described previously in the literature $[37,38]$. The filler was completely amorphous; therefore, it did not contribute to the crystalline reflexes of the composite. Moreover, the filler particles do not act as nucleating agent.

Since the signals in the registered XRD curves are symmetrical, it indicates that there are no other structures such 

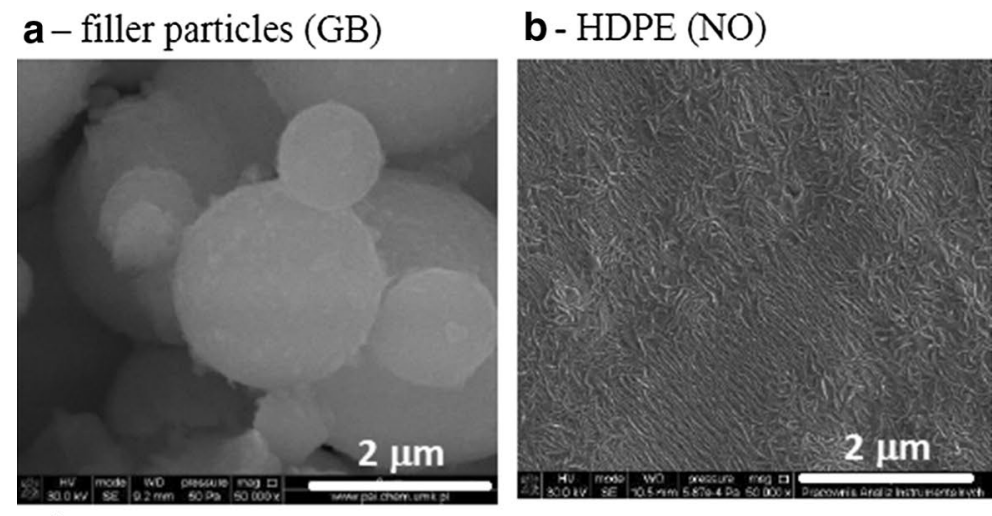

$$
\text { c - HDPE (O) }
$$

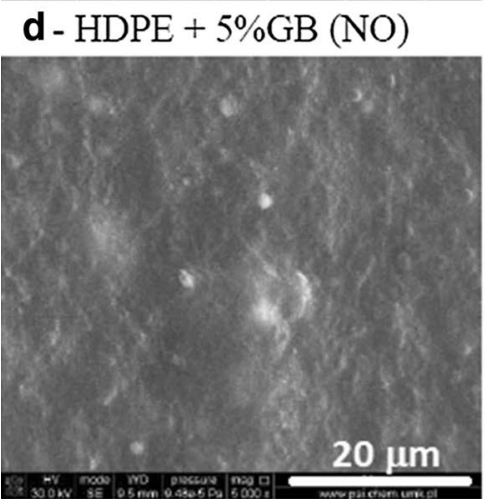

e - HDPE + 5\%GB (NO)
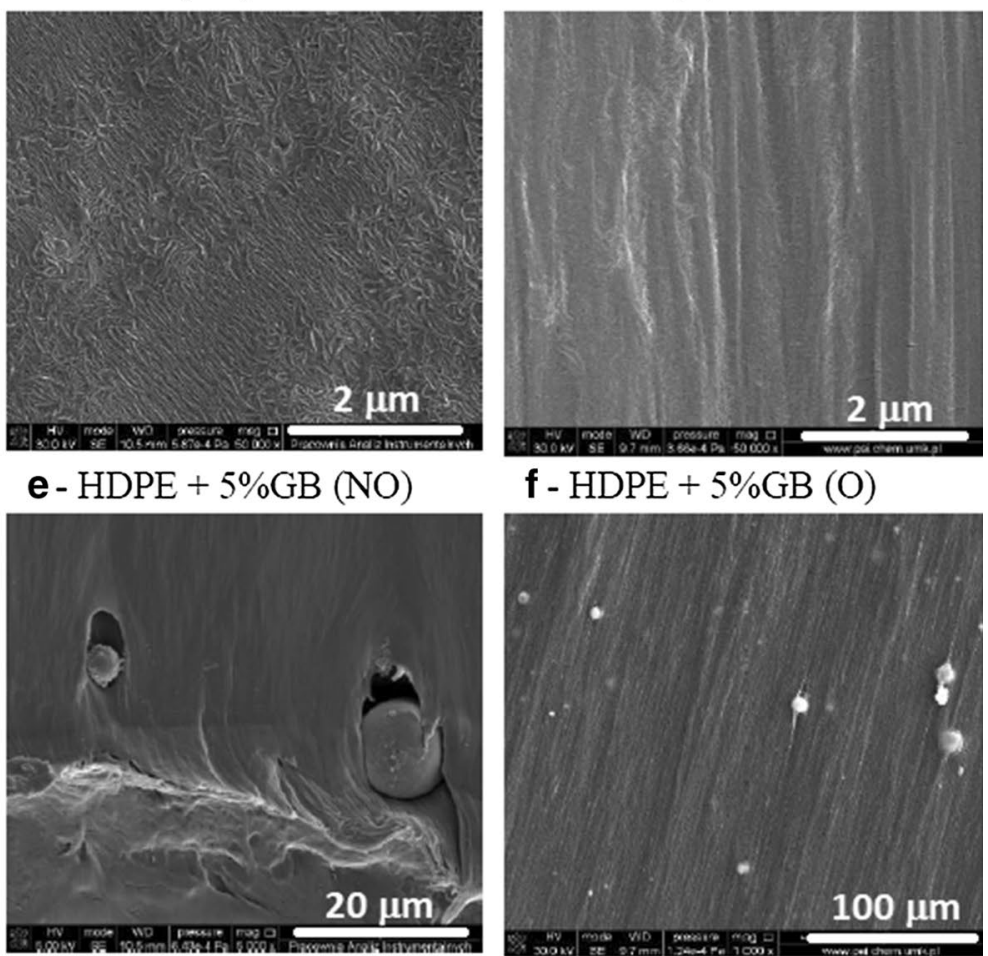

f - $\mathrm{HDPE}+5 \% \mathrm{~GB}(\mathrm{O})$
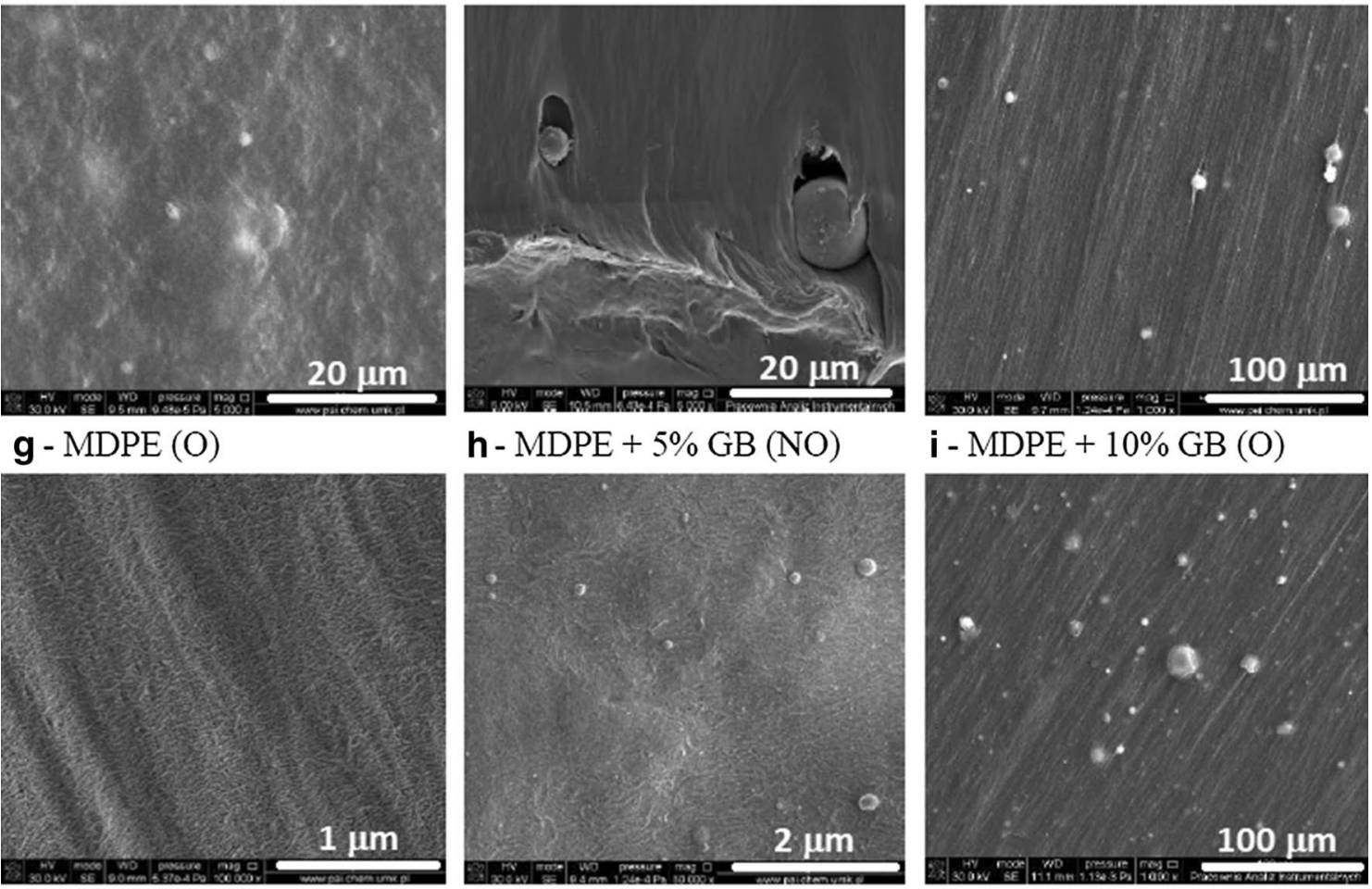

j - MDPE + $10 \%$ GB (O)

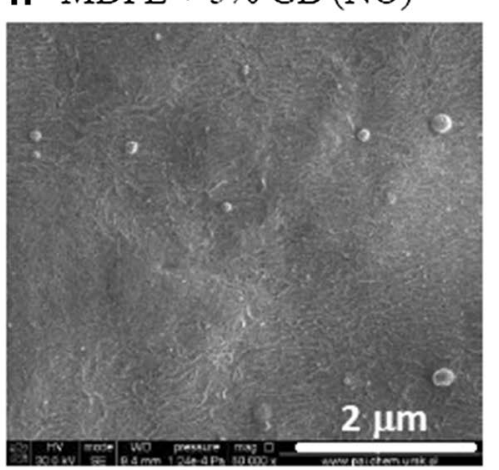

i - MDPE + 10\% GB (O)

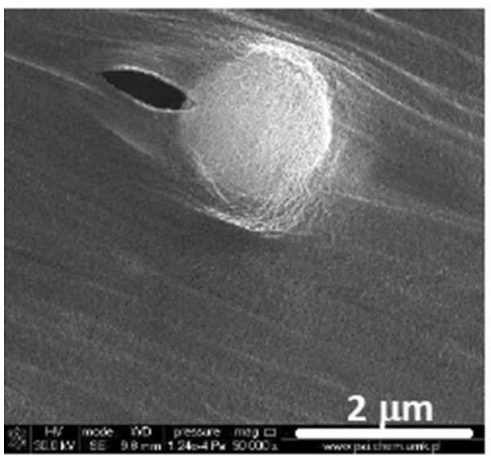

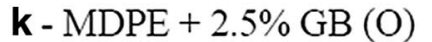

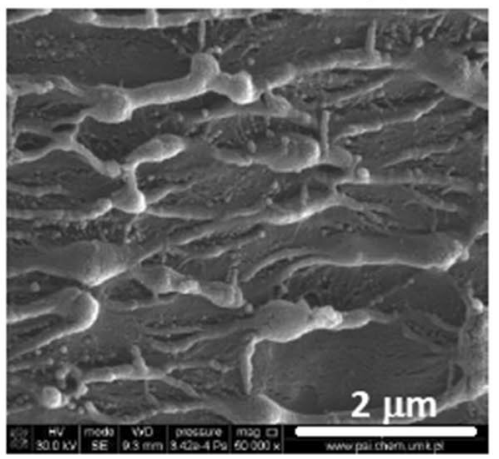

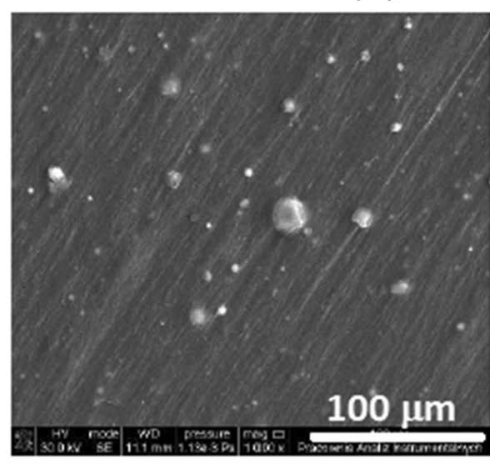

I - MDPE + 10\% GB (O)

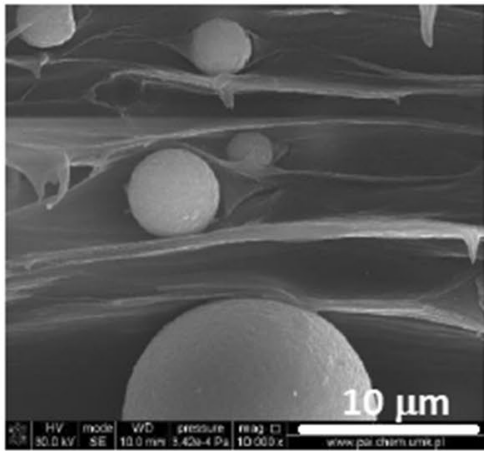

Fig. 1 Examples of SEM images of the studied materials: glass beads filler (a), HDPE and MDPE (b, c, g), and their composites with various content of GB; $N O$ non-oriented, $O$ oriented; $\mathbf{e}, \mathbf{k}, \mathbf{l}$-cross-section of the samples, the others are the surface images 

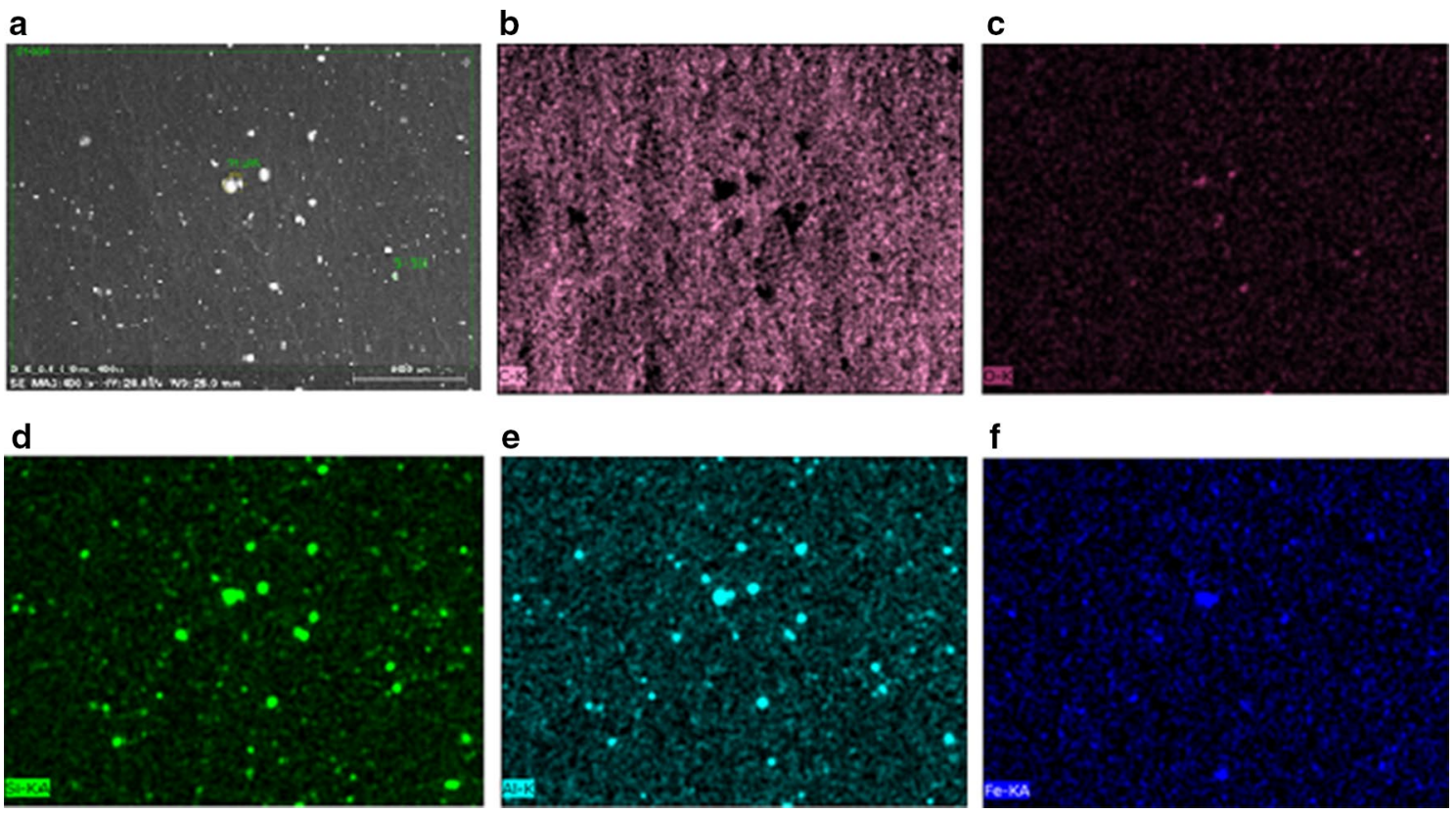

Fig. 2 SEM-EDX maps of elements in the composite HDPE +2.5\% GB (NO): a SEM at magnification $\times 400, \mathbf{b} \mathrm{C}, \mathbf{c} \mathrm{O}, \mathbf{d} \mathrm{Si}, \mathbf{e} \mathrm{Al}$, and $\mathbf{f}$ Fe. Elements with $<1 \%$ content were omitted

Fig. 3 XRD patterns of HDPE and HDPE $+10 \%$ GB (oriented and non-oriented films); the lowest flat curve concerns the filler (GB)

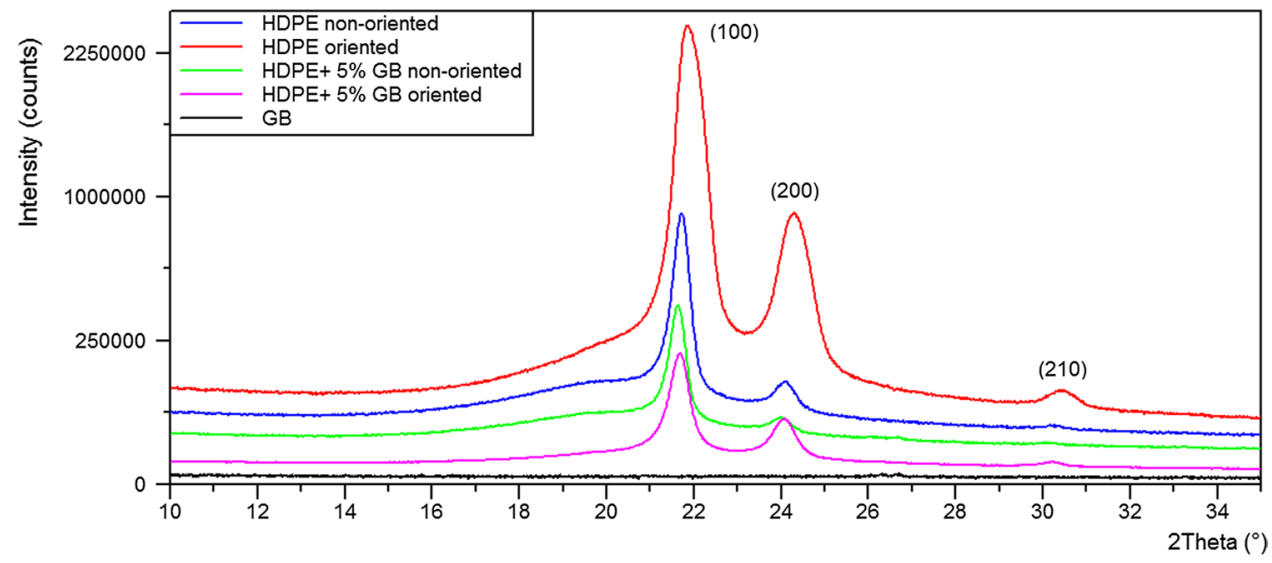

as monoclinic or hexagonal that were detected in other types of PEs [37]. Thus, XRD results suggest that both studied PEs exist in a monocrystalline structure.

The degree of crystallinity $\left(\mathrm{X}_{\mathrm{XRD}}\right)$ of the unmodified MDPE and HDPE is $52.2 \%$ and $57.4 \%$, respectively (Table 1). The addition of the filler caused insignificant changes in $\mathrm{X}_{\mathrm{XRD}}$ of the HDPE composites (changes within the experimental error) but substantial decrease in $\mathrm{X}_{\mathrm{XRD}}$ of the MDPE composites (even up to about $10 \%$ ), which indicated that the filler particles impeded the formation of the ordered MDPE structure, unlike the HDPE.

The film orientation caused the growth in the degree of crystallinity for both polyethylenes: by about $14 \%$ for HDPE and over $23 \%$ for MDPE. The alterations were also greater in the MDPE composites than in HDPE samples: the differences are about 22-24\% for the HDPE + GB and about $28-34 \%$ for MDPE + GB, i.e., up to $10 \%$ more.

There was no shift in XRD signals of the non-oriented specimens compared to the position of these XRD signals for the initial polymers, whereas slight changes in the position of the XRD signals for the oriented samples have been observed. Furthermore, the small alterations in full width at a half maximum (FWHM) of the peaks were found, which resulted from the differences in the crystallites sizes. As can be seen from the results gathered in Table 1, the addition of the GB to the polymer caused an increase in the size of the crystallites for the non-oriented composites, whereas the sample orientation caused the opposite effect. 
Table 1 Parameters from XRD patterns of non-oriented and oriented HDPE, MDPE, and their composites with glass beads (GB): crystallinity degree $\left(\mathrm{X}_{\mathrm{XRD}}, \%\right)$, position $\left(2 \Theta,{ }^{\circ}\right)$, FWHM $\left({ }^{\circ}\right)$ and share $(\%)$ of $\mathrm{PE}$ main crystalline signal and crystallites size $\left(\mathrm{L}_{110}, \mathrm{~nm}\right)$ as well as the crystallinity degree calculated from DSC $\left(\mathrm{X}_{\mathrm{DSC}}, \%\right)$

\begin{tabular}{|c|c|c|c|c|c|c|}
\hline Sample & $2 \theta\left({ }^{\circ}\right)$ & FWHM & $\%$ & $\mathrm{~L}_{110}(\mathrm{~nm})$ & $\mathrm{X}_{\mathrm{XRD}}(\%)$ & $\mathrm{X}_{\mathrm{DSC}}(\%)$ \\
\hline \multicolumn{7}{|l|}{ Non-oriented } \\
\hline HDPE & 21.7 & 0.40 & 50.3 & 20.2 & 57.4 & 59.2 \\
\hline $\mathrm{HDPE}+2.5 \% \mathrm{~GB}$ & 21.5 & 0.35 & 52.3 & 23.1 & 58.3 & 60.9 \\
\hline $\mathrm{HDPE}+5 \% \mathrm{~GB}$ & 21.6 & 0.38 & 47.7 & 21.3 & 56.6 & 58.4 \\
\hline $\mathrm{HDPE}+10 \% \mathrm{~GB}$ & 21.6 & 0.36 & 52.0 & 22.5 & 56.9 & 55.8 \\
\hline MDPE & 21.7 & 0.42 & 47.7 & 19.3 & 52.2 & 53.5 \\
\hline $\mathrm{MDPE}+2.5 \% \mathrm{~GB}$ & 21.6 & 0.39 & 43.1 & 20.7 & 48.2 & 47.6 \\
\hline $\mathrm{MDPE}+5 \% \mathrm{~GB}$ & 21.5 & 0.39 & 39.3 & 20.7 & 43.6 & 45.5 \\
\hline MDPE + 10\% GB & 21.5 & 0.39 & 39.3 & 20.7 & 42.9 & 44.3 \\
\hline \multicolumn{7}{|l|}{ Oriented $(3: 1)$} \\
\hline HDPE & 21.9 & 0.71 & 50.7 & 11.4 & 71.3 & 62.5 \\
\hline $\mathrm{HDPE}+2.5 \% \mathrm{~GB}$ & 21.7 & 0.44 & 58.9 & 18.4 & 80.1 & 71.2 \\
\hline $\mathrm{HDPE}+5 \% \mathrm{~GB}$ & 21.7 & 0.43 & 62.0 & 18.8 & 80.7 & 73.3 \\
\hline HDPE + $10 \%$ GB & 21.7 & 0.43 & 61.7 & 18.8 & 80.3 & 72.8 \\
\hline MDPE & 22.0 & 0.56 & 58.2 & 14.4 & 75.4 & 63.9 \\
\hline $\mathrm{MDPE}+2.5 \% \mathrm{~GB}$ & 21.6 & 0.43 & 60.2 & 18.8 & 77.0 & 66.6 \\
\hline $\mathrm{MDPE}+5 \% \mathrm{~GB}$ & 21.6 & 0.50 & 60.9 & 16.2 & 77.3 & 67.1 \\
\hline MDPE + 10\% GB & 21.6 & 0.43 & 61.6 & 18.8 & 76.3 & 64.3 \\
\hline
\end{tabular}

The degree of crystallinity of the polymer determined by the XRD method was compared with that found from DSC. There was a good correlation between the degree of crystallinity determined from XRD and that from DCS for the non-oriented samples. However, the degree of crystallinity of the oriented specimens determined by the XRD was by a few percent higher (ca 10\%) than that calculated from DSC data (Table 1). Similar discrepancies were observed also by other authors [37] who pointed out that DSC results led to the overestimation of amorphous phase due to the using of a two-phase model for PE.

It was proved that XRD method allows for detection an oriented non-crystalline structure, besides typical crystalline and completely amorphous phases. Our results are consistent with those obtained by Karacan [37] because the discrepancies in the calculated degree of crystallinity from XRD and DSC methods appear for the samples after the orientation process. It indicates that short-range ordering of macromolecules appears during a stretching process. These structures do not form crystallites, and thus, do not show melting point. Such arrangement can be considered as mesomorphic phase or pseudo-crystalline regions, i.e., intermediate phase between the crystalline and amorphous structures [39].

Exemplary DSC curves, which are typical of the studied samples, are shown in Fig. 4. As can be seen from the first heating run, the maximum of the main melting peak appears at $128^{\circ} \mathrm{C}$ but a small shoulder in this peak is seen at $125^{\circ} \mathrm{C}$ indicating the presence of a small amount of finer crystallites which can build thinner lamellae owing to the lower melting temperature. This small shoulder completely disappears at the second heating cycle. Moreover, the orientation of the composite films occurs at elevated temperature, i.e., $120^{\circ} \mathrm{C}$, thus, these finer structures with a lower melting point disappear. When the sample is cooled, a crystallization process occurs - the main maximum occurs at $116^{\circ} \mathrm{C}$, and the trace peak-at $79^{\circ} \mathrm{C}$.

\subsection{Mechanical properties of the polyethylene composites}

The stress-strain curves obtained for the polyethylenes and the composites during tensile tests exhibit mainly the brittle features with a small plastic area before breaking the sample. The initial straight line of the curve for which Hooke's law is fulfilled served to determine the Young's modulus. After crossing the yield point, i.e., the limit of elastic behavior, the curve of stress-strain is non-linear, which is connected with non-reversible plastic deformation. The stress increases up to maximum value, which is an equivalent to the stress at break in the non-oriented samples $\left(\sigma_{\mathrm{M}} \cong \sigma_{\mathrm{B}}\right)$, and a consequence of this is also the same value of both elongation parameters $\left(\varepsilon_{M} \cong \varepsilon_{B}\right)$. Thus, the studied samples exhibit semibrittle (or semi-ductile) fracture.

Differences during tensile tests appear in the oriented samples. HDPE and its composites undergo fracture at the maximum stress, whereas in the case of MDPE composites, after achievement of the maximum stress $\sigma_{\mathrm{M}}$, there is a significant decrease of the stress value until the sample is broken. This phenomenon, which is a typical ductile symptom, is clearly observed for MDPE $+5 \% \mathrm{~GB}$. In the case of thermoplastic polymers, such as polyolefin, the ductile properties induced by an applied load are strictly related to weaken 
Fig. 4 DSC curves of HDPE + $10 \%$ GB (non-oriented); the temperature scale is for heating runs

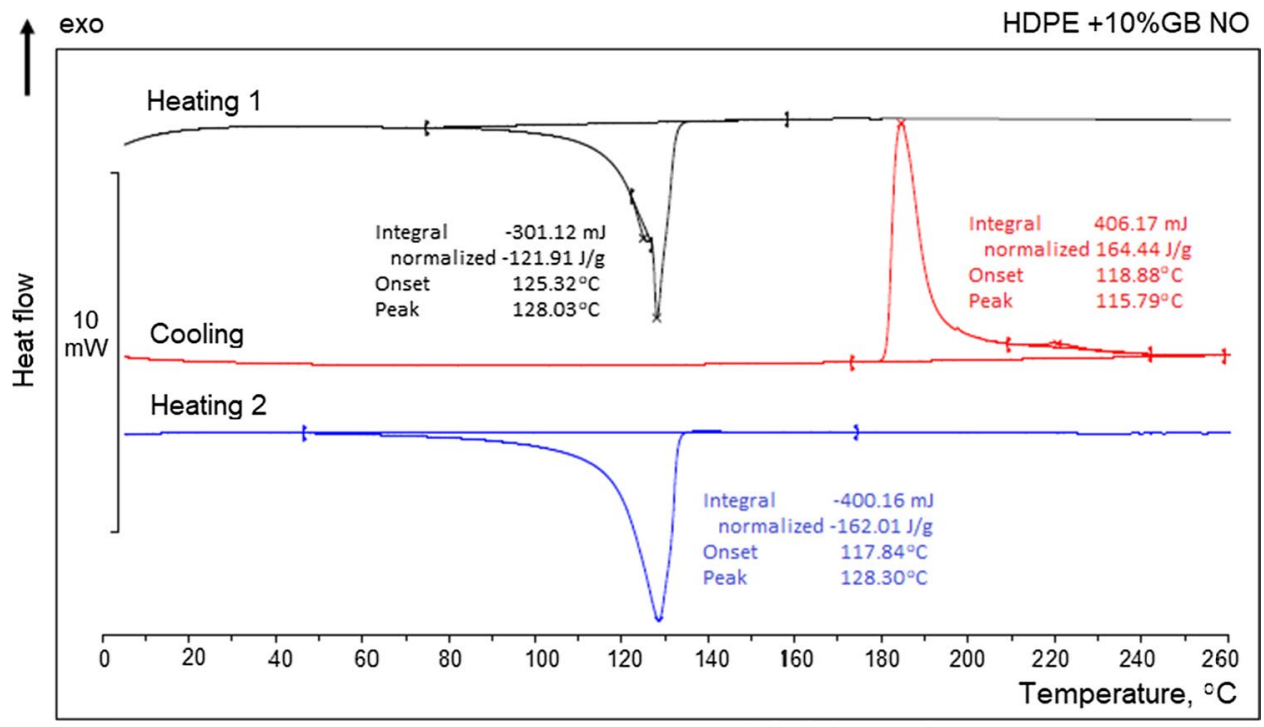

interactions between the macromolecules and consequently to the relative easier chain movements. Obviously, the presence of crystallites significantly limits the movements of the polymer chains against each other. Mechanical parameters for all studied systems are listed in Table 2.

From the point of view of piezoelectric properties, the behavior of the samples under the influence of weak forces is important; thus, the Young's modulus and initial stress should play a key role here. When weak forces act on the sample in the range of small elongation, the elastic strain vanishes after unloading. When the yield point is crossed, the plastic strain appears and deformation is irreversible.

Pristine polymeric films showed the tensile strength $\left(\sigma_{\mathrm{M}}\right)$ of 36 and $27 \mathrm{MPa}$ for HDPE and MDPE, respectively (Table 2). The Young's modulus of these samples was 596 and $421 \mathrm{MPa}$, while the strain was about $700 \%$. The orientation process caused a significant growth in $\sigma_{M}$ and $E_{t}$ for both samples, but a notable decrease in the strain (by about 4.5-6 times).

The GB addition to the polymer resulted in a different effect on mechanical properties for the non-oriented HDPE and MDPE composites. In the first case, all parameters were lower compared to the pristine HDPE (with the exception of the HDPE $+2.5 \% \mathrm{~GB}$, where the Young's modulus was somewhat greater than for the pristine HDPE). For MDPE filled with GB, $E_{t}$ decreased, but a small increase in the tensile strength (both $\sigma_{\mathrm{M}}$ and $\sigma_{\mathrm{B}}$ ) was noticed. The elongation of the non-oriented MDPE composites was significantly higher than that for the non-oriented HDPE with GB.

There is no simple relation between the evaluated mechanical parameters and the filler content. HDPE-based composites had higher Young's moduli values than the MDPE composites. Among the oriented composites, the highest Young's modulus was for the HDPE with 5 and $10 \%$
Table 2 Mechanical parameters for the non-oriented and oriented HDPE, MDPE, and their composites with glass beads filler

\begin{tabular}{|c|c|c|c|c|c|}
\hline Sample & $\sigma_{\mathrm{M}}(\mathrm{MPa})$ & $\sigma_{\mathrm{B}}(\mathrm{MPa})$ & $\varepsilon_{\mathrm{M}}(\%)$ & $\varepsilon_{\mathrm{B}}(\%)$ & $\mathrm{E}_{\mathrm{t}}(\mathrm{MPa})$ \\
\hline \multicolumn{6}{|l|}{ Non-oriented } \\
\hline HDPE & 36 & 36 & 694 & 695 & 596 \\
\hline $\begin{array}{l}\mathrm{HDPE}+2.5 \% \\
\text { GB }\end{array}$ & 27 & 27 & 560 & 560 & 601 \\
\hline $\mathrm{HDPE}+5 \%$ GB & 26 & 25 & 527 & 531 & 578 \\
\hline $\begin{array}{l}\mathrm{HDPE}+10 \% \\
\text { GB }\end{array}$ & 25 & 23 & 491 & 500 & 562 \\
\hline MDPE & 27 & 26 & 680 & 681 & 421 \\
\hline $\begin{array}{l}\mathrm{MDPE}+2.5 \% \\
\mathrm{~GB}\end{array}$ & 32 & 32 & 867 & 872 & 401 \\
\hline $\mathrm{MDPE}+5 \% \mathrm{~GB}$ & 30 & 30 & 583 & 585 & 302 \\
\hline $\begin{array}{l}\mathrm{MDPE}+10 \% \\
\mathrm{~GB}\end{array}$ & 31 & 30 & 601 & 603 & 278 \\
\hline \multicolumn{6}{|l|}{ Oriented (3:1) } \\
\hline HDPE & 112 & 30 & 113 & 124 & 949 \\
\hline $\begin{array}{l}\mathrm{HDPE}+2.5 \% \\
\text { GB }\end{array}$ & 93 & 93 & 110 & 110 & 715 \\
\hline $\mathrm{HDPE}+5 \%$ GB & 100 & 100 & 99 & 99 & 809 \\
\hline $\begin{array}{l}\mathrm{HDPE}+10 \% \\
\text { GB }\end{array}$ & 99 & 84 & 92 & 106 & 860 \\
\hline MDPE & 107 & 107 & 148 & 148 & 746 \\
\hline $\begin{array}{l}\text { MDPE }+2.5 \% \\
\text { GB }\end{array}$ & 94 & 26 & 81 & 100 & 748 \\
\hline $\mathrm{MDPE}+5 \% \mathrm{~GB}$ & 105 & 22 & 37 & 84 & 771 \\
\hline $\begin{array}{l}\text { MDPE + } 10 \% \\
\text { GB }\end{array}$ & 108 & 60 & 66 & 72 & 753 \\
\hline
\end{tabular}

GB and MDPE + 5\% GB. Simultaneously, the MDPE + GB films became ductile, with moderate ultimate elongation.

$\sigma_{\mathrm{B}}$ value of the oriented HDPE (without GB) differs from that for the oriented HDPE with GB, which is due to the gradual breaking of the stretched chains in a wide range 
of forces. This sample contains fibers that break at forces greater than applied for the non-oriented sample, but the complete break of the sample occurs at much lower force, which gives an average breaking strength of about $30 \mathrm{MPa}$.

Generally, one can state that the good mechanical properties of both types of polymers result from their ordered structure, as evidenced by rather high value of the degree of crystallinity. The macromolecules contain only short branches because the tested polymers were copolymers of ethylene with hexene-1. The lack of long side-chains made them easier to create the compact regular arrangement.

The GB particles introduced into the polymer are not only a source of inhomogeneity but also contribute to the formation of microcracks that are able to weaken the material. In heterogeneous materials energy is not distributed uniformly in the whole sample but it is concentrated around inclusions, cavities and defects. The same situation can concern implemented electrical charges during polarization process.

On the other hand, the filler particles and the holes in the composites are responsible for the formation of durable electrets in the polymer composites. Therefore, it is so important to choose the appropriate sample composition and the preparation conditions (filler content, size and shape of particles, conditions of extrusion, and orientation of films) to obtain the system with the best properties.

From the point of view of piezoelectric properties, piezomaterials are subjected to relatively weak forces, but their resistance to higher mechanical loads may be required for other potential applications, e.g., during energy harvesting from moving cars.

\subsection{Thermal stability of the polyethylene composites}

Thermal stability of the samples is another useful property of the studied materials. This is related to both the processing and their use at elevated temperatures. For this purpose, the thermogravimetric analysis (TGA) of the samples was carried out. Some examples of TG/DTG analysis are shown in Fig. 5.

TGA curves indicate that all systems are stable up to $460{ }^{\circ} \mathrm{C}$ and decompose in one step. The pristine polymers almost totally degrade $(99-100 \%)$ at $500{ }^{\circ} \mathrm{C}$ but composites not. The glass filler is a solid residue (proportional to the introduced amount) at this temperature. DTA curves show two endotherms: the first-associated with the melting of the crystalline phase in PE (which is not accompanied by the mass loss) and the second-related to the total degradation of the macromolecules. The melting temperature determined by this method coincides with the values obtained by DSC.

As can be seen in the Table 3, there are no significant differences between the parameters determined for HDPE and MDPE. Moreover, the filler and the orientation had negligible influence on the polyethylenes thermal stability. The melting temperature $\left(\mathrm{T}_{\mathrm{m}}\right)$ of all examined systems was in the range of $126-130{ }^{\circ} \mathrm{C}$ and was nearly independent on the sample composition.

Detailed analysis of TG/DTG curves let us distinguish the subtle differences in the studied samples. One can notice that the degradation onset temperature $\left(\mathrm{T}_{\mathrm{o}}\right)$ of the non-oriented MDPE is somewhat higher than that for HDPE but the situation changes in the case of the oriented samples. The largest alteration due to the orientation has been observed for MDPE (reduction in $\mathrm{T}_{\mathrm{o}}$ by $12{ }^{\circ} \mathrm{C}$ when compared to the MPDE non-oriented). The degradation rate $\left(V_{\mathrm{m}}\right)$ was highest for the non-oriented MDPE but for the remaining samples the decomposition process underwent with the same speed.

\subsection{Piezoelectric properties of the polyethylene composites}

Because polyethylene in a non-polar material, all studied samples have been subjected to polarization in a constant electric field of $100 \mathrm{~V} / \mu \mathrm{m}$ at $85^{\circ} \mathrm{C}$ using contact electrodes. During this process, the electric charge has been implemented into the composite film and accumulated in traps, which can be structural defects such as filler particles and cavities.

Piezoelectric charge and voltage was systematically measured up to ca. 2-5 months of storage at room temperature. The obtained data are presented for $100 \mathrm{kPa}$ stress value.

The results of charging of the non-modified MDPE and HDPE as well as the behavior of these films during storage are shown in Fig. 6. As can be seen from the data presented, the non-oriented HDPE film polarizes to a negligible extent and after about 40 days it depolarizes. The oriented HDPE reaches a high charge value, however, after 5 days that sample significantly loses its charge with a further downward trend. The non-oriented MDPE film achieves a large polarization charge, but, it depolarizes over the entire storage period. The MDPE oriented film reaches a small piezoelectric charge that stabilizes after about 20 days. It should also be noted that the polarization of the film changes with the orientation of the film. The non-oriented samples have a polarization with the direction opposite to the direction of the polarizing field, i.e., they have a heterocharge, whereas the oriented films have polarization in the direction of the polarizing field, i.e., they have a homocharge. Both films without the filler have been eliminated from further tests as not meeting the requirements for stable dipoles.

The PE composites behaved differently-the measured values of piezoelectric charge and voltage were much higher than those for virgin polyethylenes (Figs. 7 and 8). The oriented MDPE with $10 \%$ of the filler content was the exception. For this film, the electric breakdown was observed, so the measurements were impossible. It may result from too 
Fig. 5 TG, DTG and DTA curves for MDPE and its composites with 5 and $10 \% \mathrm{~GB}$ : a non-oriented, $\mathbf{b}$ oriented
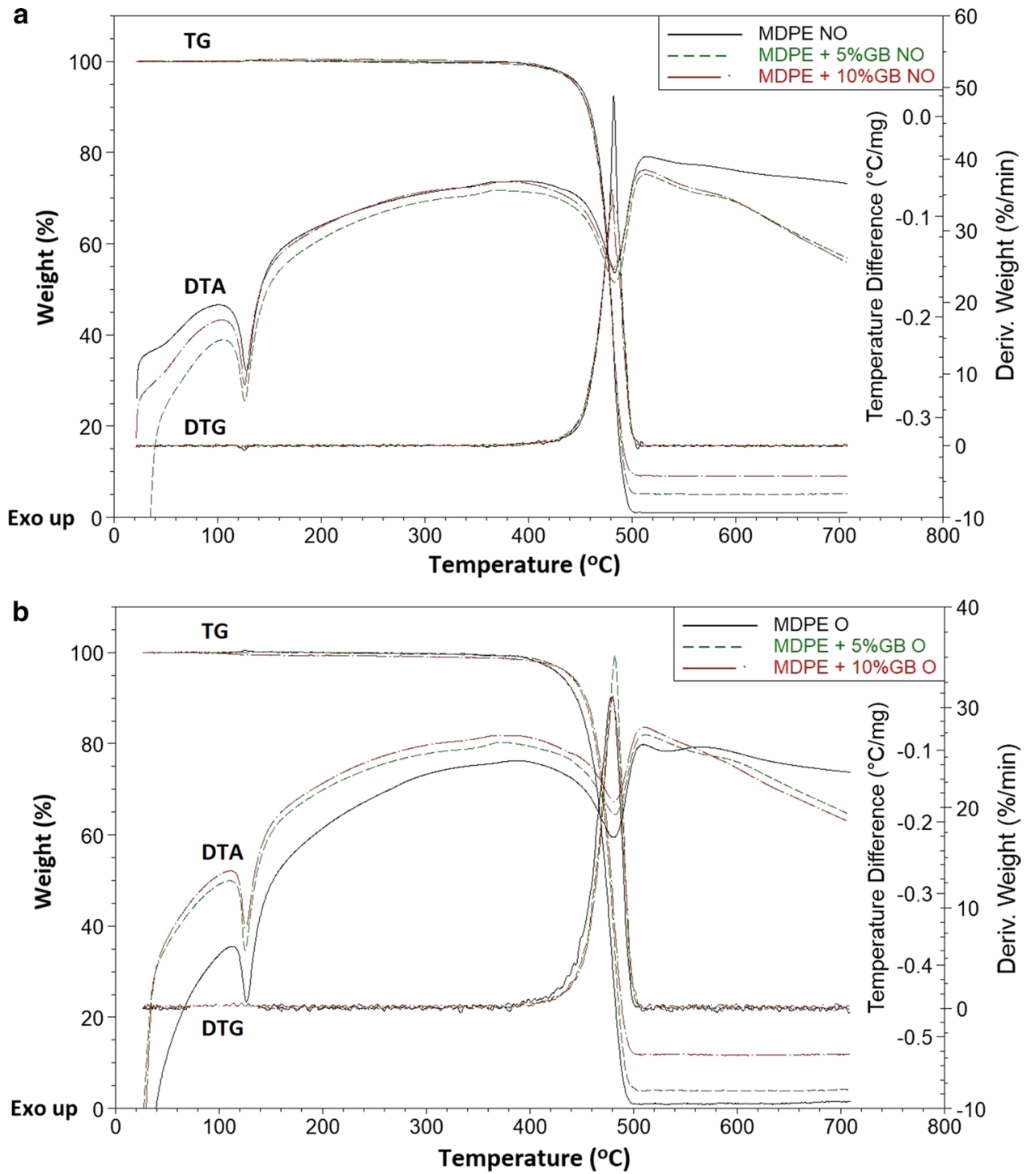

high heterogeneity of the sample and microcracks formed during stretching. Such tiny cracks can be the precursors of sample breaking. In the case of HDPE with $10 \%$ of the filler content, the polarization was achieved successfully.

Figures 7 and 8 show a slight reduction in $q$ and $V$ values of the composites at the beginning of the storage; however, after a few days, these parameters stabilize. This initial relatively modest fall in the charge was mainly due to the relaxation processes occurring at the surface, during of which the charges were partially neutralized.

Particularly good piezoelectric properties were noticed for the oriented MDPE + 5\% GB. Among the HDPE composites, the oriented HDPE with $10 \%$ filler exhibited the best piezoelectric properties; however, they were weaker than that for the mentioned MDPE composite.

The charge $\left(\mathrm{d}_{33}\right)$ and the voltage $\left(\mathrm{g}_{33}\right)$ piezoelectric coefficients (in the direction perpendicular to the sample surface, consistent with the direction of the electric field in selected electrets) were determined from the obtained results for different stresses. The piezoelectric coefficient, called also piezoelectric modulus, expresses the polarization or the electric field generated in electret per unit of the stress applied. In other words, it is the electrical response of the material to the working mechanical force.

Figures 9 and 10 present the decreasing values of the charge and voltage piezoelectric coefficients $\left(\mathrm{d}_{33}\right.$ and $\left.\mathrm{g}_{33}\right)$ with increasing applied stress, which is typical behavior of polymeric systems observed previously [17, 18].

The highest value of the piezoelectric coefficient $d_{33}$ was obtained for the oriented MDPE with 5\% of GB, i.e., $\sim 100 \mathrm{pC} / \mathrm{N}$ for lower stresses $\left(\sim 10 \mathrm{kPa} / \mathrm{cm}^{2}\right)$ and $\sim 60 \mathrm{pC} / \mathrm{N}$ for higher stresses $\left(\sim 120 \mathrm{k} \mathrm{Pa} / \mathrm{cm}^{2}\right)$. The coefficient $\mathrm{g}_{33}$ was in the range of $4-8 \mathrm{Vm} / \mathrm{N}$ for this sample, depending on the stress applied. For the non-oriented MDPE films having the same composition, the values of both coefficients was lower at least twice and more. 
Table 3 Thermal parameters for the non-oriented and oriented HDPE, MDPE, and their composites with glass beads filler

\begin{tabular}{|c|c|c|c|c|c|}
\hline Sample & $\mathrm{T}_{\mathrm{o}},{ }^{\circ} \mathrm{C}$ & $\mathrm{T}_{\max },{ }^{\circ} \mathrm{C}$ & $\Delta \mathrm{m}, \%$ & $\mathrm{~T}_{\mathrm{m}},{ }^{\circ} \mathrm{C}$ & $\mathrm{V}_{\max }, \% / \min$ \\
\hline \multicolumn{6}{|l|}{ Non-oriented } \\
\hline HDPE & 464 & 483 & 99 & 129 & 35 \\
\hline $\begin{array}{l}\mathrm{HDPE}+2.5 \% \\
\text { GB }\end{array}$ & 467 & 483 & 97 & 130 & 36 \\
\hline $\mathrm{HDPE}+5 \% \mathrm{~GB}$ & 467 & 484 & 96 & 129 & 37 \\
\hline $\begin{array}{l}\mathrm{HDPE}+10 \% \\
\text { GB }\end{array}$ & 466 & 484 & 90 & 127 & 35 \\
\hline MDPE & 470 & 482 & 99 & 128 & 48 \\
\hline $\begin{array}{l}\mathrm{MDPE}+2.5 \% \\
\mathrm{~GB}\end{array}$ & 467 & 484 & 97 & 127 & 36 \\
\hline $\begin{array}{l}\text { MDPE }+5 \% \\
\text { GB }\end{array}$ & 464 & 482 & 95 & 126 & 37 \\
\hline $\begin{array}{l}\text { MDPE }+10 \% \\
\text { GB }\end{array}$ & 465 & 481 & 91 & 126 & 29 \\
\hline \multicolumn{6}{|l|}{ Oriented (3:1) } \\
\hline HDPE & 466 & 483 & 99 & 130 & 36 \\
\hline $\begin{array}{l}\mathrm{HDPE}+2.5 \% \\
\text { GB }\end{array}$ & 459 & 480 & 97 & 128 & 30 \\
\hline $\mathrm{HDPE}+5 \% \mathrm{~GB}$ & 464 & 483 & 95 & 129 & 34 \\
\hline $\begin{array}{l}\mathrm{HDPE}+10 \% \\
\text { GB }\end{array}$ & 466 & 483 & 91 & 129 & 34 \\
\hline MDPE & 458 & 478 & 100 & 127 & 31 \\
\hline $\begin{array}{l}\mathrm{MDPE}+2.5 \% \\
\mathrm{~GB}\end{array}$ & 464 & 484 & 97 & 126 & 37 \\
\hline $\begin{array}{l}\text { MDPE }+5 \% \\
\text { GB }\end{array}$ & 463 & 482 & 96 & 126 & 35 \\
\hline $\begin{array}{l}\text { MDPE + } 10 \% \\
\text { GB }\end{array}$ & 463 & 480 & 88 & 126 & 31 \\
\hline
\end{tabular}

Relatively high values were also obtained for the oriented HDPE films with GB: $d_{33}$ changes from about 70 to $40 \mathrm{pC} / \mathrm{N}$ and $\mathrm{g}_{33}$-from 6 to $3 \mathrm{Vm} / \mathrm{N}$ with increasing stress. These values are comparable to those for MDPE $+5 \%$ GB. It can be noticed that the differences between the determined piezoelectric coefficients for the oriented HDPE composites were insignificant when the content of the filler was changing; however, the highest values of $\mathrm{d}_{33}$ and $\mathrm{g}_{33}$ were observed for HDPE with $10 \%$ of GB.

\subsection{Discussion of piezoelectric properties}

Piezoelectric properties of polymeric composites strongly depend on the chemical nature of dielectric constituents, their distribution, molecular interactions and the sample morphology. Electrets in polyethylene can be created by simple modification - introducing an appropriate amount of a mineral filler of a specified size as well as mechanical orientation of the composite films. Both these physical factors affect not only the piezoelectric properties but also the hardness, the melting temperature (i.e., working temperature), and the degree of crystallinity of the polymer. In addition, it turned out that also the type of polymer can influence the properties of the composites.

It is known that PE microstructure, thus, also properties depend on the synthesis method and conditions including the type of catalyst applied [40-42]. The microstructure of PE is determined by the number and length of branched chains, as well as the type of end groups in macromolecules. Generally, in HDPE, there are stronger interactions between the regular chains than in MDPE because of its more branched structure, which makes MDPE more susceptible to deformation. Both studied polymers were obtained by copolymerization of ethylene and hexane-1, which led to a defined linear structure with the repeated branching of the same length [43]. Some differences in the properties of HDPE and LDPE can be explained by the subtle variations in the chemical structure and macromolecular ordering in both matrix polymers.

The detailed ATR-FTIR analysis in the range of $\mathrm{C}-\mathrm{H}$ deformation vibrations showed only the slight differences in the degree of branching (Fig. 11). The bands at $1378 \mathrm{~cm}^{-1}$ and at $1368 \mathrm{~cm}^{-1}$ corresponding to $\mathrm{CH}_{3}$ and
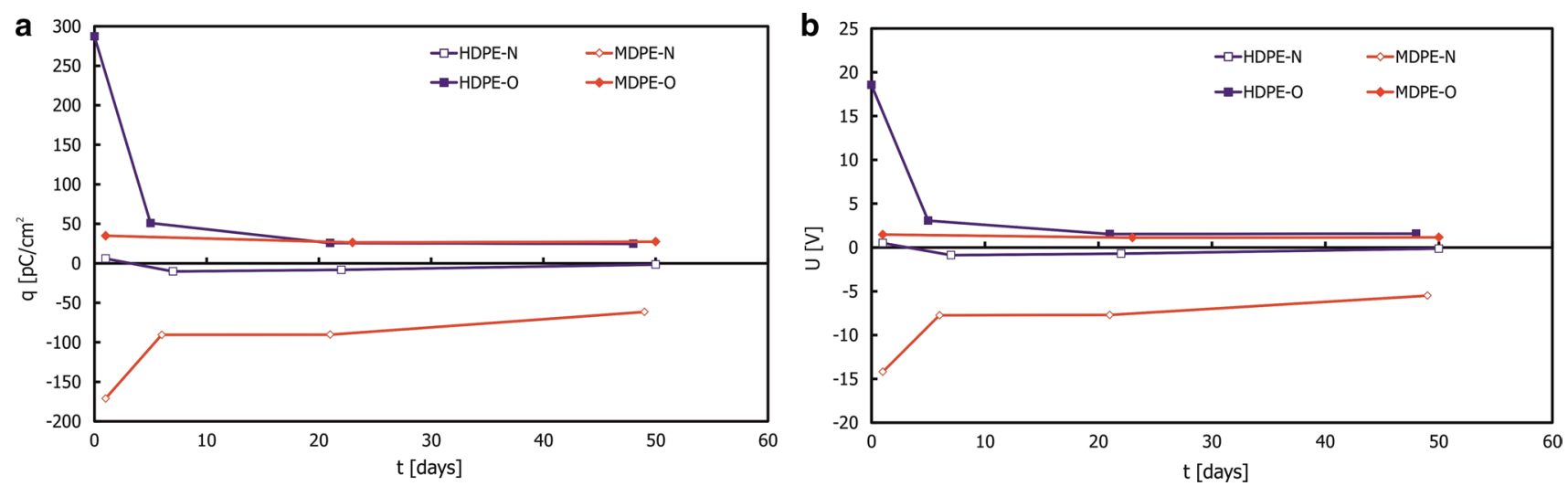

Fig. 6 The dependence of piezoelectric charge (a) and voltage (b) on storage time of MDPE and HDPE film: oriented (O) and non-oriented (N) 

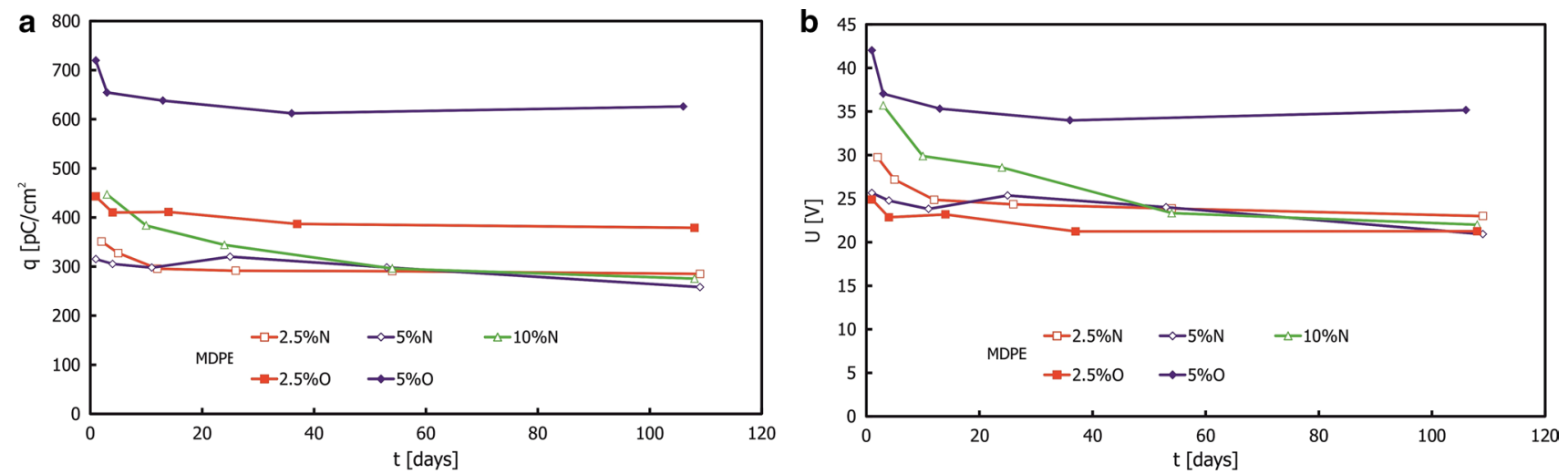

Fig. 7 The dependence of piezoelectric charge (a) and voltage (b) on storage time of the oriented (O) and non-oriented (NO) MDPE films with glass beads (GB)
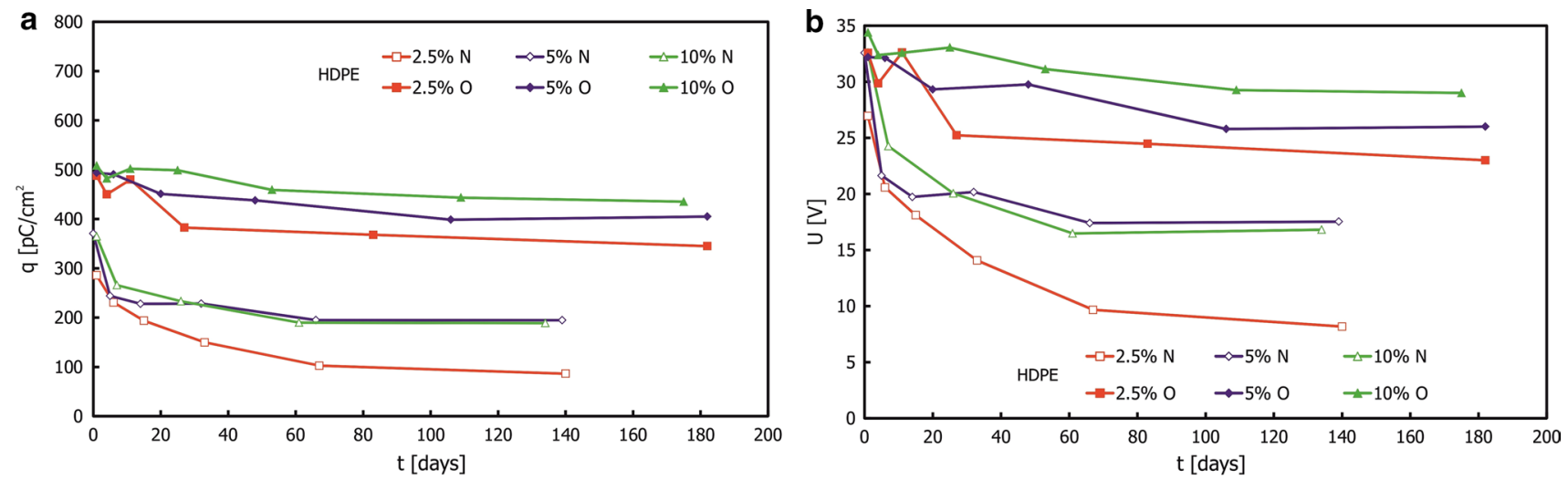

Fig. 8 The dependence of piezoelectric charge (a) and voltage (b) on storage time of the oriented (O) and non-oriented (NO) HDPE films with glass beads (GB)
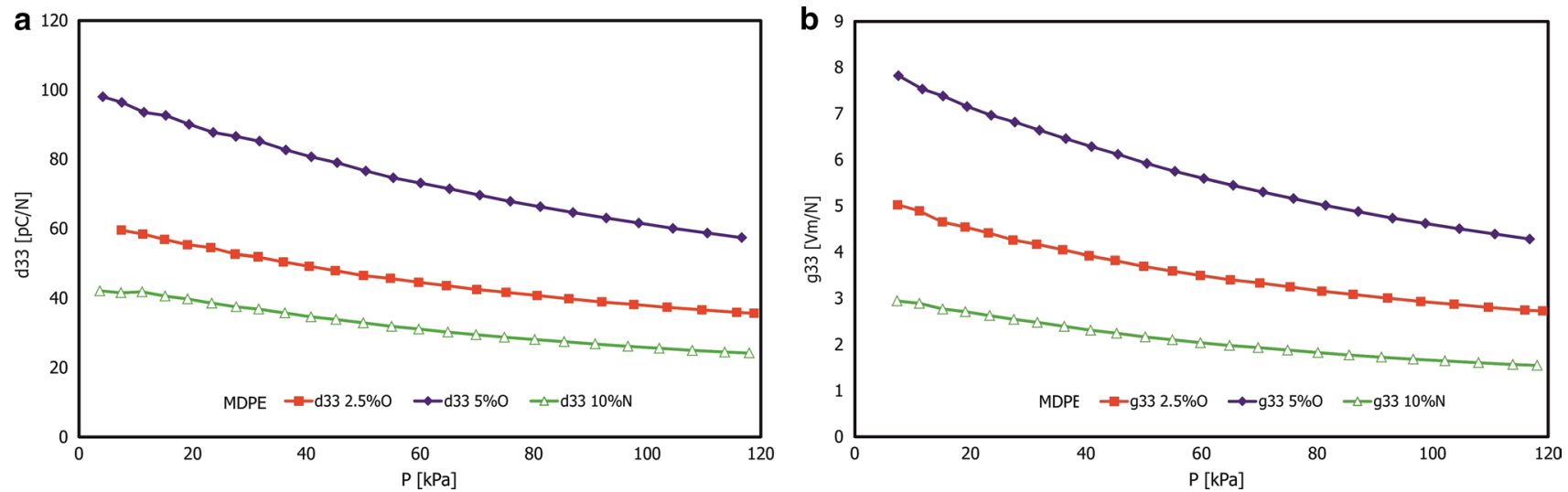

Fig. 9 Dependence of piezoelectric coefficients: $\mathbf{a}$ charge $\mathrm{d}_{33}$ and $\mathbf{b}$ voltage $\mathrm{g}_{33}$ on stress for the oriented MDPE films with 2,5 and 5\% GB as well as the non-oriented MDPE with 10\% GB

$\mathrm{CH}_{2}$ symmetric scissoring vibrations, respectively, have been used for estimation of the degree of branching. The calculated ratio of the integral intensities $\mathrm{r}=\mathrm{I}_{\mathrm{CH} 3}(1378)$ /
$\mathrm{I}_{\mathrm{CH} 2}$ (1368), obtained after the spectra deconvolution (Fig. 12), was somewhat higher for MDPE $(\sim 0.10)$ than that for HDPE $(\sim 0.07)$. The slightly greater degree of 

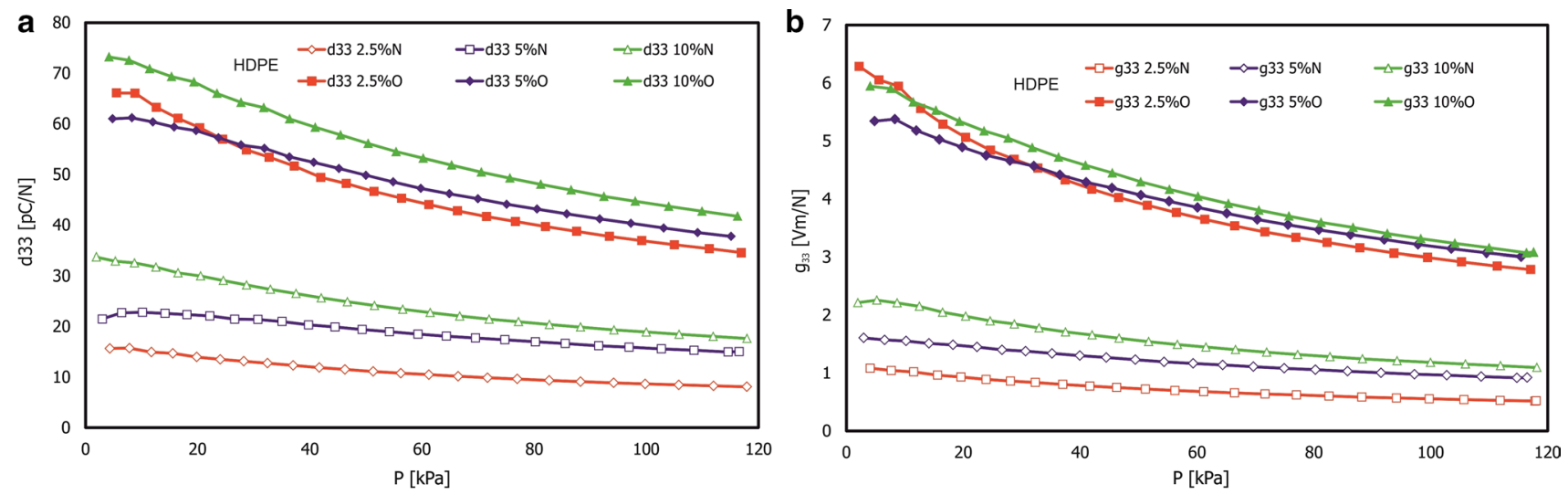

Fig. 10 Dependence of piezoelectric coefficients: $\mathbf{a}$ charge $\mathrm{d}_{33}$ and $\mathbf{b}$ voltage $\mathrm{g}_{33}$ on stress for the non-oriented and oriented HDPE composites with $2.5,5$ and $10 \%$ GB

Fig. 11 Comparison of ATRFTIR spectrum of MDPE and HDPE film in the range of $1300-1400 \mathrm{~cm}^{-1}$ (after normalization and deconvolution)

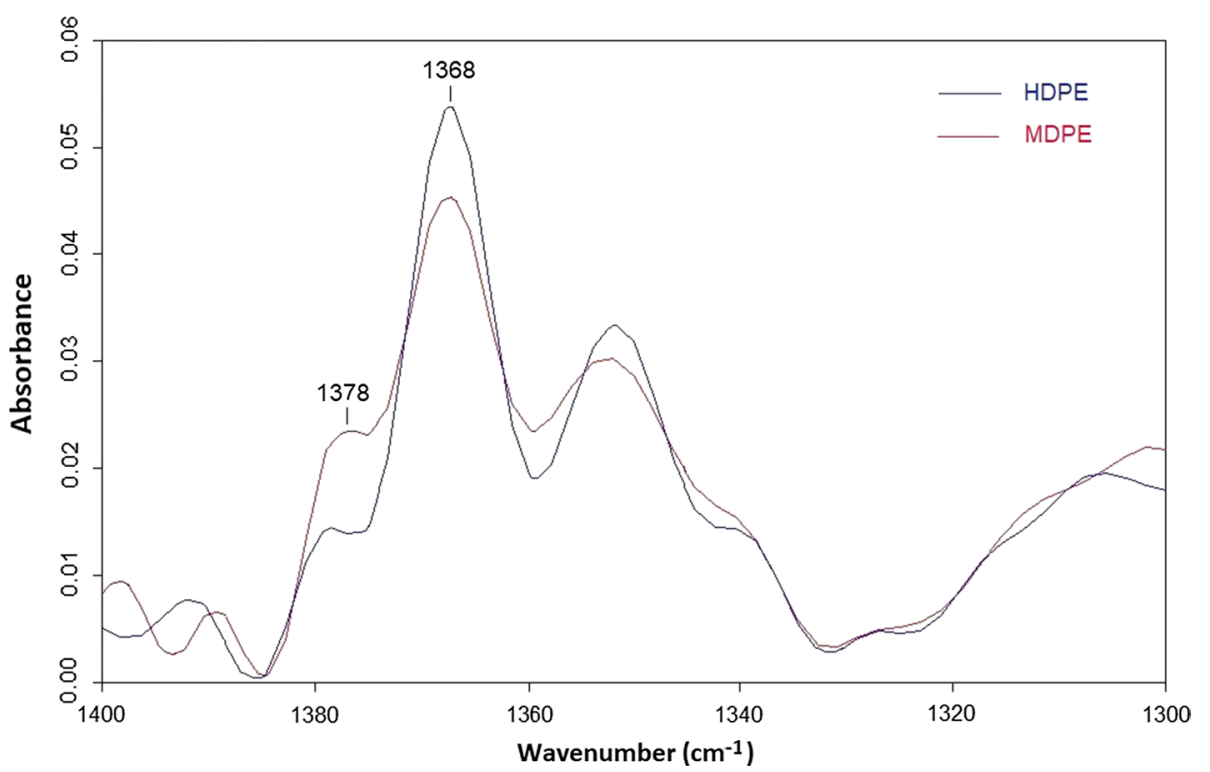

branching in MDPE is reflected in its smaller degree of crystallinity as confirmed by XRD and DSC studies. The lower degree of crystallinity and consequently lower polymer density influences the microstructure and the composite properties.

It is worth emphasizing that such slight alteration in the structure of macromolecules in pure MDPE and HDPE (without filler) does not affect the piezoelectric properties, or rather lack thereof. However, these small structural differences may be the reason for the differentiation of composite morphology, which in turn affects the formation of electrets.

A good dispersion of the GB in the polymer matrix is possible during the extrusion of the film at the temperature in which the polymer is melted. The morphology of the samples (observed in SEM images) is formed during the cooling of the melted polymer to room temperature. At this time, crystallization and "freezing" of the created cavities occurs.
The presence of GB in the PE matrix results in obtaining the materials with good piezoelectric properties and in slight deterioration in mechanical strength. But there is no distinct influence of the filler on the thermal stability of the composites.

The orientation process leading to the further macromolecules ordering has a strong effect on piezoelectric properties of the composites. The reorganization of the composite structure, induced by stretching, concerns both amorphous and crystalline phase. In addition to the typical relaxation processes, the crystallites may be displaced or can become more perfect, while the amorphous or poorly ordered areas in the polymer can be incorporated into the crystallites [44].

The comparison of the degree of crystallinity determined by XRD and DSC methods led to the conclusion that the imperfectly ordered intermediate phase may be formed during the stretching of the samples, which 
Fig. 12 Results of curve fitting of ATR-FTIR spectra in the range of $1320-1390 \mathrm{~cm}^{-1}$ for: a HDPE film, b MDPE film. The following data of band deconvolution are included into the component bands used for calculation: a height (absorbance), (FWHM, $\mathrm{cm}^{-1}$ ) and an integral intensity (i.e., area) of a peak
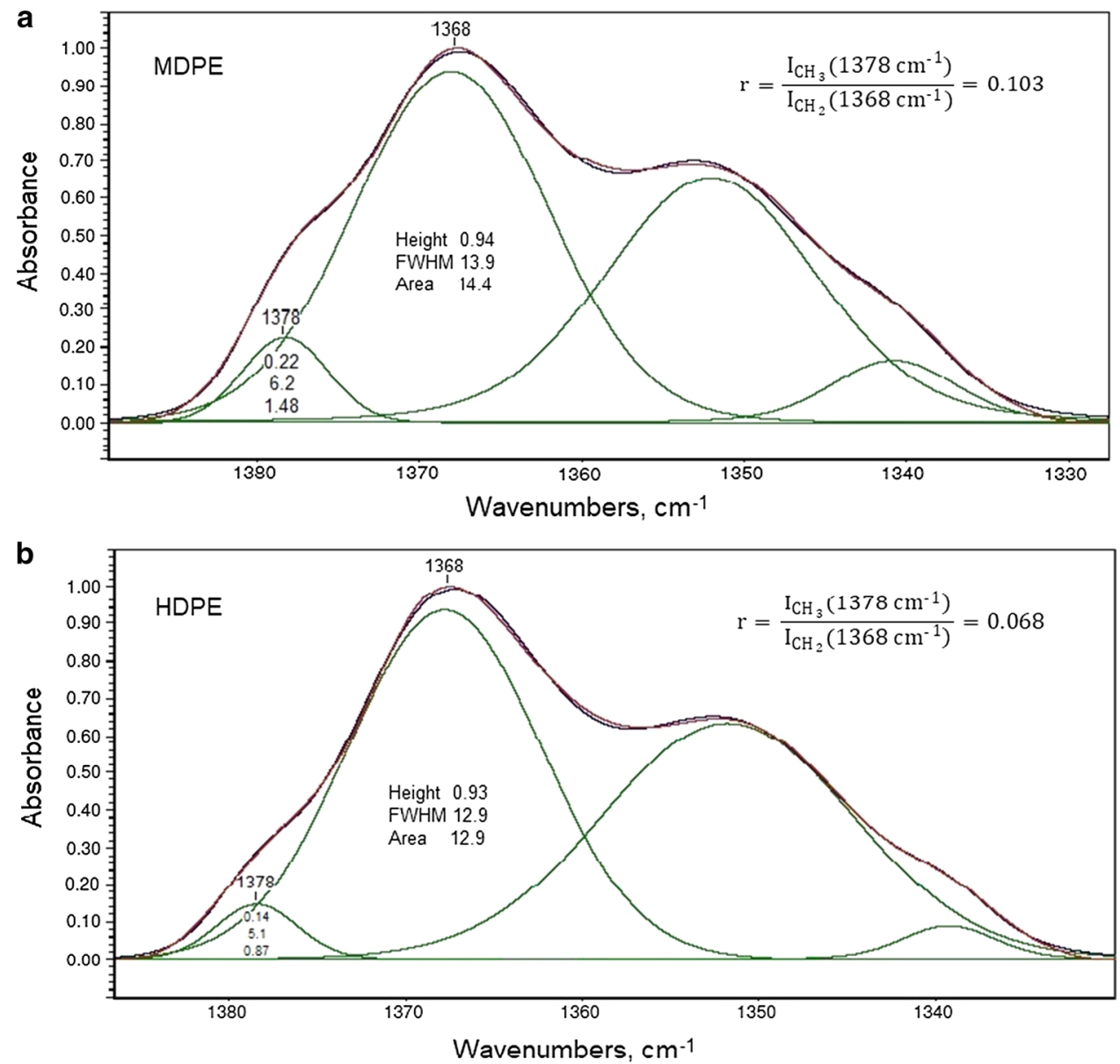

significantly affects the polarization of the molecules in the system and consequently the stability of electrets. Moreover, partial separation of GB from the macromolecules takes place because of weak interfacial adhesion caused by lack of matrix polarity. This contributes to changing the shape and enlarging the cavities in which the electrical charge is trapped as schematically illustrated in Fig. 13.
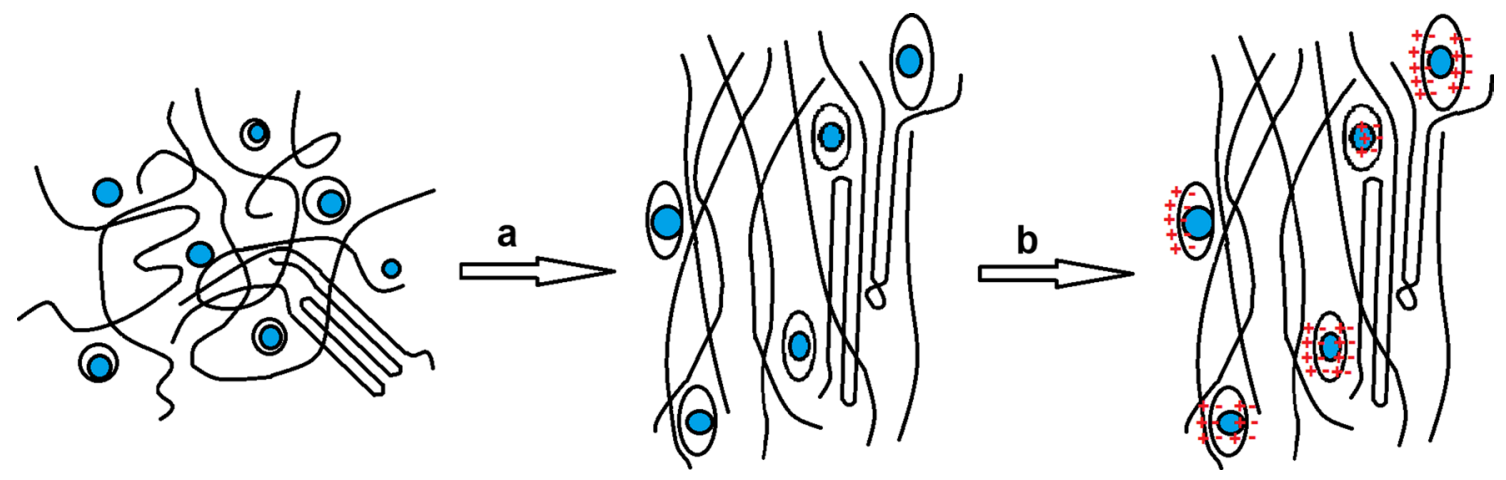

Fig. 13 Simplified scheme of PE + GB composite morphology; a orientation, $\mathbf{b}$ poling process. The blue spheres illustrate the GB particles dispersed in the polymer matrix. Apparent layers around the filler beads mean empty spaces that change shape during stretching. In the charging process, these cavities are the places where the electric charges can accumulate 


\section{Conclusions}

This study allowed to explain the effect of the silica filler and the orientation process on the structure and piezoelectric properties of PE composites. The effective method of preparation of the piezoelectric films with the glass beads was developed-the extrusion conditions were optimized and the appropriate composition was selected. Although the structure of the obtained samples was heterogeneous, the dispersion of the filler particles in the polymer matrix was relatively uniform, as confirmed by the SEM/EDX analysis.

The introduced glass beads were responsible for the cavities formation inside the PE film, which promoted the accumulation of electric charges. It has been found that uniaxial orientation at 3:1 ratio was also an important factor contributing to the growth in the macromolecular ordering and significant improvement of piezoelectric properties. Probably, the mesomorphic phase is created in a the stretched PE, and imperfect crystallites also play an important role in the creation of electrets.

The mechanical properties were much better for the oriented composites than for the non-oriented ones. However, a comparison with the virgin oriented polymers generally indicates a slight decrease in $\mathrm{E}_{\mathrm{t}}, \sigma_{\mathrm{M}}$ and elongation, which is typical of non-homogenous systems. Around the filler the voids were formed and contributed to faster composite cracking under the influence of stresses.

The type of polyethylene (high or medium density), the content of the mineral fillers, as well as the orientation process practically do not affect the thermal stability of the composites.

The best piezoelectric properties were exhibited by the oriented film of MDPE with 5\% GB, which was a result of appropriate molecular arrangement and an internal cellular structure. The HDPE-based composites are the systems with good piezoelectric properties too. Maintaining the strictly defined processing and orientation conditions ensures the production of piezomaterials with repeatable structure and properties.

The determined piezoelectric coefficients for these composites are high, which indicates that they have better piezoelectric properties than well-known poly(vinylidene fluoride) $[1,2,5]$.

Summarizing, the obtained PE composites have satisfactory piezoelectric properties, which predisposes these materials to practical applications. Ease of production, availability and low price of raw materials is a great advantage of piezopolymer production.

Acknowledgements This research was supported by the National Science Centre, Poland (Grant No. 2015/17/B/ST8/03396). The authors thank Mr Andrzej Cichocki (ITE, Kraków) for the conducting the measurements of piezoelectric properties and MSci Grzegorz Sionkowski (UMK, Toruń) for spectra deconvolution.

Open Access This article is distributed under the terms of the Creative Commons Attribution 4.0 International License (http://creativeco mmons.org/licenses/by/4.0/), which permits unrestricted use, distribution, and reproduction in any medium, provided you give appropriate credit to the original author(s) and the source, provide a link to the Creative Commons license, and indicate if changes were made.

\section{References}

1. S. Bauer, F. Bauer, Piezoelectricity, vol. 114, Springer Series in Materials Science (Springer, Berlin, 2008), pp. 157-177

2. K.S. Ramadan, D. Sameoto, S. Evoy, Smart Mater. Struct. 23, 0330001 (2014)

3. M.M. Houc, Materials analysis in forensic science (2016), https ://books.google.pl/books?isbn=0128006730. Accessed 29 May 2019

4. J. Parui, D. Saranya, S.B. Krupanidhi, in Micro and Smart Devices and Systems, Springer Tracts in Mechanical Engineering, ed. by K. Vinoy, G. Ananthasuresh, R. Pratap, S. Krupanidhi (Springer, New Delhi, 2014), pp. 303-315

5. H. Li, C. Tian, Z.D. Deng, Appl. Phys. Rev. 1, 041301 (2014)

6. M.J. Guan, W.-H. Liao, J. Intell. Mater. Syst. Struct. 19(6), 671680 (2008)

7. C.H. Yang, Y. Song, M.S. Woo, J.H. Eom, G.J. Song, J.H. Kim, J. Kim, T.H. Lee, J.Y. Choi, T.H. Sung, Sens. Actuator A 261, 317-324 (2017)

8. H. Xiong, L. Wang, Appl. Energy 174, 101-107 (2016)

9. I. Jung, Y.-H. Shin, S. Kim, J.-Y. Choi, C.-Y. Kang, Appl. Energy 197, 222-229 (2017)

10. C.Y. Chen, C.Y. Tsai, M.H. Xu, C.T. Wu, C.Y. Huang, T.H. Lee, Y.K. Fuh, Express Polym. Lett. 13(6), 533-542 (2019)

11. C. Ribeiro, V. Sencadas, D.M. Correia, S. Lanceros-Méndez, Colloids Surf. B 136, 46-55 (2015)

12. E. Fukada, Biorheology 32(6), 593-609 (1995)

13. A.H. Rajabi, M. Jaffe, T.L. Arinzeh, Acta Biomater. 24, 12-23 (2015)

14. L.J. Romasanta, M.A. Lopez-Manchado, R. Verdejo, Prog. Polym. Sci. 51, 188-211 (2015)

15. X. Lu, H. Qu, M. Skorobogatiy, Sci. Rep. 7, 2907 (2017)

16. C.R. Bowen, V.Y. Topolov, H.A. Kim, Modern Piezoelectric Energy-Harvesting Materials, vol. 238, Springer Series in Materials Science (Springer, New York, 2016)

17. H. Kaczmarek, B. Królikowski, E. Klimiec, J. Kowalonek, J. Mater. Sci.: Mater. Electron. 28, 6435-6447 (2017)

18. H. Kaczmarek, M. Chylińska, E. Klimiec, B. Królikowski, G. Sionkowski, M. Machnik, Pure Appl. Chem. 91(6), 967-982 (2019)

19. H. Kaczmarek, E. Klimiec, B. Królikowski, M. Chylińska, M. Machnik, J. Mater. Sci.: Mater. Electron. 28, 16639-16647 (2017)

20. Q. Hamdi, F. Mighri, D. Rodrigue, AIMS Mater. Sci. 5(5), 845869 (2018)

21. E. Audet, F. Mighri, D. Rodrigue, A. Ajji, Cell. Polym. 37, 103119 (2018)

22. N. Jahan, F. Mighri, D. Rodrigue, A. Ajji, J. Appl. Polym. Sci. 136, 47540 (2019)

23. M. Müller, Agron. Res. 15(S1), 1107-1118 (2017)

24. J.Z. Liang, R.K.Y. Li, S.C. Tjong, Polym. Test. 19, 213-220 (2000) 
25. D.J. Chimeni, E. Vallée, L. Sorelli, D. Rodrigue, Polym. Eng. Sci. 58, 1826-1836 (2018)

26. R. Jeziorska, A. Szadkowska, M. Zielecka, M. Wenda, Polym. Degrad. Stab. 145, 70-78 (2017)

27. https://mol.hu/images/pdf/Vallalatiugyfeleknek/polimer_terme kek/hdpe-kozepes-esnagysurusegu_polietilenek/fs-471-02_eng. pdf. Accessed 29 May 2019

28. https://www.granulat.com.pl/media/pdf/26797784711bc6646b68 cdbbd45f5e31.pdf. Accessed 29 May 2019

29. https://www.yumpu.com/en/document/read/7180532/mintr on-7tm-product-data-sheet-rocktron. Accessed 29 May 2019

30. M. Abareshi, S.M. Zebarjad, E.K. Goharshadi, J. Compos. Mater. 43, 2821-2830 (2009)

31. R. Masirek, E. Piotrowska, A. Gałęski, A. Hiltner, E. Baer, Macromolecules 41, 8086-8094 (2008)

32. S.M. Lindley, G.C. Flowers, J.E. Leffler, J. Org. Chem. 50(5), 607-610 (1985)

33. D. Arencón, J.I. Velasco, Materials 2(4), 2046-2094 (2009)

34. A. Pawlak, A. Gałęski, A. Różański, Prog. Polym. Sci. 39, 921$958(2014)$

35. A. Rozanski, A. Gałęski, Macromolecules 44, 7273-7287 (2011)

36. B. Królikowski, H. Kaczmarek, E. Klimiec, M. Chylińska, D. Bajer, Polimery 64, 29-34 (2019)
37. I. Karacan, Fibres Text. East. Eur. 13, 4 (52), 15-21 (2005)

38. M. Chipara, B. Jones, D.M. Chipara, J. Li, K. Lozano, S. Valloppilly, D. Sellmyer, e-Polymers 17(4), 303-310 (2017)

39. G. Allegra, Interphases and Mesophases in Polymer Crystallization I (Springer, Berlin, 2005)

40. N.M.G. Franssen, J.N.H. Reek, B. de Bruin, Chem. Soc. Rev. 42, 5809-5832 (2013)

41. K. Czaja, M. Białek, A. Utrata, J. Polym. Sci. A 42, 2512-2519 (2004)

42. K. Czaja, M. Białek, Polymer 42, 2289-2297 (2001)

43. M. Białek, K. Czaja, B. Sacher-Majewska, Polimery 48, 645-648 (2003)

44. K. Pielichowska, K. Pielichowski, in Progress in Understanding of Polymer Crystallization, ed. by G. Reiter, G.R. Strobl (Springer, Berlin, 2007), pp. 427-434

Publisher's Note Springer Nature remains neutral with regard to jurisdictional claims in published maps and institutional affiliations. 